\title{
Revolution of Nursing Science in the Next Decade
}

\author{
Phatcharapon Tulyakul ${ }^{1} \&$ Soontareeporn Meepring ${ }^{2}$ \\ ${ }^{1}$ Nurse Instructor, Borommarajonani College of Nursing, Trang, Thailand \\ ${ }^{2}$ Assistant professor, Department of Nursing, Faculty of Nursing, Naresuan University, Phitsanulok, Thailand \\ Correspondence: Soontareeporn Meepring, Department of Nursing, Faculty of Nursing, Naresuan University, \\ Phitsanulok, Thailand. Tel: 66-55-966-700 Ext.6721.
}

Received: December 21, 2020 Accepted: Februay 16, 2021 Online Published: Februay 24, 2021

doi:10.5539/gjhs.v13n4p32 URL: https://doi.org/10.5539/gjhs.v13n4p32

\begin{abstract}
Knowing a history of nursing science allows nurses to understand the journey of nursing theorists and scientists in developing the nursing science. Since the era of Florence Nightingale in the mid- $18^{\text {th }}$ century, the nursing theories and nursing research were published to the public, particularly scientific community. During late $18^{\text {th }}$ and $19^{\text {th }}$ century, there were many interesting questions among these debates that have not been answer yet, such as is it a nursing science or science of nursing? and is it a pure science or applied science? Even though the scientific community acknowledges that nursing is known as a science, many scholars remain to discuss the definition and category of nursing science.

Along the history of nursing knowledge development, nursing scholars faced many challenges concerning the difficulty to develop the required content for nursing practices, to be an excellent discipline in the developing science base, to prepare nurse researchers, and to disseminate research results to the community and to the public (Hinshaw, 1989). Nowadays nursing science is entering into the postmodern era and it will be continued development in the next decade. Even if nurses do not recognise that nursing knowledge is currently in crisis, looking for the future of nursing science throughout the principle of Kuhn's paradigm shift might provide valuable direction for nurse. Therefore, this paper aims to explain Kuhn's revolutionary theory and its principle. Moreover, the influence of Kuhn's revolution theory on the revolution of nursing science that will be present in this paper.
\end{abstract}

Keywords: Kuhn's revolution theory, nursing science, next decade

\section{Introduction}

\subsection{Kuhn's Revolution Theory}

The revolution theory was developed by Thomas Kuhn with his inspiration in solving the problem when he encountered the out-of-date scientific theory (Kuhn, 1996). Kuhn (1996) identified the malfunction or crisis of scientific theory as a prerequisite of revolution. The older paradigms might be in crisis when the external influencers outside the science developed or changed, such as social, economic, intellectual, and technological factors (Kuhn, 1996). To end the crisis, the revolution, therefore, is an alternative approach (Kuhn, 1996). The consequences of the revolution allow scholars to see and respond to different worldviews (Kuhn, 1996).

The shift of vision and perception toward the older paradigms establish the gap between the traditional and evolutional paradigm (Kuhn, 1996). The rejection of the old paradigms created paradigm choices as an initiative of the transformation or evolution of new paradigms (Kuhn, 1996). Kuhn (1996) explained the principle of the revolution that "scientific revolutions are here taken to be those non-cumulative developmental episodes in which an older paradigm is replaced in whole or in part by an incompatible new one" (p. 92). Furthermore, Kuhn (1996) declared that "In the evolution of science, new knowledge would replace ignorance rather than replace knowledge of another and incompatible sort" (p. 95). Therefore, the evolution of scientific thinking does not destroy and refute the past scientific paradigms, but it allows scholars to cumulate or emerge the predecessors to a higher-level or growth of science (Kuhn, 1996).

\section{Type of Revolution}

Because of the ambiguity of Kuhn's paradigm and scientific revolution, many scholars attempted to clarify its notion and definition for the better understanding (Kvasz, 2014; Tuboly, 2017). Thus, Kvasz (2014) categorized the scientific revolutions based on the Kuhnian principle into four types: idealizations, re-coding, relativizations, 
and re-formulations. The idealization is defined as "the change of ideal objects" (Kvasz, 2014, p.81); while the re-coding is the creation of the linguistic framework of idealities-the paradigm of representation (Kvasz, 2014). The relativization of scientific revolution represent the common unities and differences inside the framework of previous re-coding-the paradigm of reification, whereas the re-formulation is a change of formulation terms or language of science (Kvasz, 2014). To consider a portion of these four types of revolution, re-formulation is the smallest magnitude; whilst idealization is the greatest one (Kvasz, 2014).

\section{What is the Definition of Nursing Science?}

Even though nurses are familiar with the terms of nursing science, it seems that no one can provide clear and concise its definition because the definition of nursing science is an enigma (Barrett, 2002). Moreover, Barrett (2017) stated that "communicating a clear definition of nursing science to the public will change how society thinks about nursing, and that change will reverberate" (p.129). Therefore, before thinking about the revolution of nursing science, it is necessary that nurses should understand the definition of nursing science.

Surprisingly, only a few definitions of nursing science were presented in the literature (Barrett, 2002). All of them were published in the Nursing Science Quarterly Journal. To begin with the definitions in 1997, some nursing scholars were asked to define the definitions of nursing science in which they expressed it in different perspectives. Daly (1997) defined nursing science as follows:

An identifiable, discrete body of knowledge comprising paradigms, frameworks, and theories. Nursing science is in development; it will continue to evolve. Its evolution will be facilitated through extension of inquiry into nursing research and practice methods which are driven by nursing's paradigms and theories. (p.10)

Besides, Takahashi (1997) provided its definition as "a unique human science which focuses on phenomena related to human health. Nursing science focuses on the quality of life for each person. Nursing science as a human science will become more developed and elaborated through unique research methods during the 21st century (p.11). While Parse et al. (2000) defined the famous definition in terms of nursing theory-guided practice as follows:

Nursing theory-guided practice is a human health service to society based on the discipline-specific knowledge articulated in the nursing frameworks and theories. The discipline-specific knowledge reflects the philosophical perspectives embedded in the ontological, epistemological, and methodological processes that frame nursing's ethical approach to the human-universe-health process. (p.177)

Nevertheless, three common threads of these three definitions present as follows: 1) nursing science is the human science, 2) nursing paradigms, frameworks, and theories generate nursing knowledge, and 3) nursing science is in progress and its development is impelled by nursing research.

\section{The Influence of Kuhn's Revolution Theory on the Revolution of Nursing Science}

Many scholars believe in the utilities of the Kuhn's revolution theory in terms of principle of paradigm shift and revolution; therefore, it might be a good choice for nursing scholars to investigate the development of nursing science through this lens. As this may be another tool for us to get ready to meet the anticipated health and social care demands from 2020 to 2030.

\section{What are the Malfunctions and Crisis of Nursing Knowledge?}

According to the Kuhnian revolutionary theory, paradigm shift arises when anomalies of the older paradigms are recognized. To ponder the revolution of nursing science in the next decade, nursing scholars, therefore, should analyze and criticize the malfunctions and crisis of existing nursing knowledge. Identifying the anomalies of nursing knowledge is a challenging task among nursing scholars because little is known about this issue. Based on the literature review, two main issues of nursing knowledge anomalies were published.

The first, Grace, Willis, Roy, and Jones (2016) stated that "the future of nursing as a discipline is at a dramatic crossroads" (p. 62). Grace et al. (2016) explained more about the current maturation of nursing science is in danger of losing the identity of nursing because of external distractive influences. Interdisciplinarity is one external factor that influences on the crisis of nursing knowledge (Grace et al., 2016; Parse, 2015a). For the reason that nurses overlook the unique of nursing knowledge, they chose to conduct research based on other disciplines rather than the nursing theories (Grace et al., 2016; Parse, 2015a). Furthermore, research funding involves as a cause of this issue because the external funding put nursing research away from nursing's unique foci and substantive areas of nursing inquiry (Grace et al., 2016; Parse, 2015a). Parse (2015a) pointed out that funding was a dilemma among nurse scientists, for example, the research supported by the National Institutes of Health (NIH) was rarely conceptualized within a nursing framework or theory.

The second, Barrett (2017) mentioned that "the extant nursing theories and frameworks are in danger of extinction" 
(p. 132). Barrett (2017) declared that this danger arose from unclear definition and foci of nursing science. The dilemma arguments concerning nursing science or science of nursing and nursing is a basic science or applied science never done. Moreover, Barrett (2017) pointed out that nursing theory-guided practice approach was a missing part of nursing science that nurses faced a difficulty in integrating nursing theories into their nursing practices. Consequently, nursing frameworks and theories became invisible. Importantly, Barrett (2017) warned that nurses and nursing scholars should realize this crisis issue "before nursing theories are silently erased from the blackboard of nursing science" (p. 132).

\section{What will be the Revolution of Nursing Science?}

In furtherance of diminish or dispose of the anomalies of nursing science, the revolution must occur. As mentioned above, two main crises of nursing science are: 1) losing the identity of nursing influenced by the external influences and 2) vague definition and foci of nursing science. Under these phenomena, the nursing science should evolve for the existence of the nursing discipline.

No one really knows what nursing science will look like in the next decade, but literature review provides the idea for speculating its future. To predict the future of nursing science, this retrospective analyze is generated based on Kuhnian revolution theory. In the light of Wall and Carraro, (2009), Kuhnian perspective had an influence on the development of the nursing framework and theories, because metaparadigm of each nursing theory was developed under the concept of paradigm. Eventually, metaparadigm become the identity of nursing theories in which the concept of human being, environment, health, and nursing must be defined. Forasmuch as nursing science does not have a core metaparadigm and the metaparadigm of each theory is different, the revolution nursing science should occur within their own theories.

According to the principle of Kuhn's paradigm shift, Wall and Carraro (2009) explained the development of the nursing theories that "different theories have key points that converge and more recent theories, that is, new theories aim to refute or overthrow older theories (p. 419). Therefore, the revolution of nursing theories will happen when anomalies are presented by nursing research (Wall \& Carraro, 2009). Furthermore, new paradigms of nursing science must be a free expression of art, science, and knowledge to preserve the uniqueness of nursing (Wall \& Carraro, 2009).

In the hope that the revolution of nursing in the next decade will establish the obvious foci of nursing knowledge based on the identity of nursing. Inasmuch as nursing scholars realize the influences of the external factors that affect the change of nursing science, nursing scholars must be careful and thoughtful when transforming any components of nursing science. It cannot deny that the revolution of nursing science influenced by the development of technology, health science, biological science, behavioral science, health phenomena, society, economy, and politics (Henly et al., 2015a; Henly et al., 2015b; Parse, 2016). As a result, nursing scholars are facing the new challenge in cumulating those factors into the extent nursing paradigms without reduction the core of nursing science.

In the historical creation of nursing science, many nursing theories were developed based on the borrowed theories, such as physiology, psychology, biology, social science, and behavioral science (Peterson \& Bredow, 2009). It is reasonable if those borrowed theories changed, nursing theories must be evolved. In addition, Henly (2011) forecasted the future of nursing science that "in the word of 2026, nursing science is grounded in revolutionary biological discoveries by the human health and illness experience, including nursing transections" (p. 81). Likewise, Parse (2016) and Patricia (2017) recommended that biological and behavioral sciences should embrace in nursing science with the purpose that nursing scientists will be able to compete with scientists of other disciplines. For example, omics sciences are the revolution of biology that related to "understanding of health and disease, including interventions for disease prevention, health protection, health promotion, and self-management" (Conley et al., 2015, p. 426).

Many nursing scholars recommended that omics should be incorporated into nursing knowledge as a new direction of nursing inquiry to understand the development of human being and human health (Conley et al., 2015; Henly, et al., 2015b). To integrate omics to nursing science, nursing scholars, however, must keep nursing unique contributions, especially nursing frameworks and conceptual models. In addition, Conley et al. (2015) suggested that nursing scholars could include omics methods to interpret research findings and develop nursing interventions. In doing this, the best way of adding omics in nursing science is to re-construct nursing metaparadigm and conceptual frameworks.

Another external influencer that should be considered for the revolution of nursing science is an advanced of science and technology that are comprised of e-science, informatics and big data, and patient-reported outcomes 
(Henly et al., 2015a; Henly et al., 2015b). Since innovative technology establishes an alternative approach for the advancement of nursing science and healthcare, these advanced methods should be aligned on the boundaries of knowledge in nursing science (Henly et al., 2015b). Nursing science can definitely take advantage of innovative technologies by integrating them into conceptual frameworks and metaparadigm. For instance, the paradigm of environment and nursing in self-care theory should be re-defined by including the notions of innovative technologies as supported tools for self-management, such as wearable health devices and robotics for real-time nursing monitoring and intervention (Henly et al., 2015b; Patricia, 2017). It is not only the technology that are comprised of e-science, but also nursing practice in the new era will occur within more regulated related to health care systems, with a much higher focus on the cost and the quality of the service that is delivered. As patients will appear more complex illnesses and treatment regimens that will require to nurses to have appropriate levels of education, experience, and clinical specialization.

Furthermore, the digital revolution creates the new paradigm of science, called e-science (Henly et al., 2015a; Jankowski, 2007). Henly (2011) asserted that "nursing e-science is continually updated and informed by e-Nightingale, where the core values and goals of nursing practice are expressed in virtual therapeutic environments transcending time and space (p. 81). The enterprise of e-science refers to a big data, computing resources, and high-performance visualization enabled by the Internet will change people's attitude and behavior, a relationship between nurses and clients, and research methodology (Henly et al., 2015a; Jankowski, 2007).

For the future of nursing science in the digital era, high-performance of technologies will have a huge impact on the nursing research and practice, particularly nursing informatics. For example, big data that are produced on the websites and in large databases, such as YouTube, social media, and electric health record (EHR) will be extraordinarily developed (Salzmann-Erikson \& Eriksson, 2015). Virtual environments in the cyberspace will be increasingly used in the nursing discipline in terms of virtual self-care and online care (Salzmann-Erikson \& Eriksson, 2016). As the consequence of this change, nursing metaparadigm should be refined again. Salzmann-Erikson and Eriksson (2016) provided a paradigm shift of self-care that differed from Orem's self-care theory without reduction of the older paradigm of Orem. Salzmann-Erikson \& Eriksson (2016) declared that virtual self-care could be as a concept for the contemporary nursing theories in which Orem's theory was enhanced to the new paradigm.

It seems that the growth of advanced technology alters the future of nursing science. Owing to the development of technologies, another evolutional form of nursing science is scopes of nursing research in which new knowledge of health's complexity and nursing outcomes in real-world phenomena are addressed (Henly et al., 2015a). In the next decade, the nursing research methodology will focus significantly on innovative study designs, analytic methods for patient-centered outcomes research, comparative effectiveness research, and community-based participatory research (Henly et al., 2015a). Therefore, $\mathrm{PhD}$ nursing education should refine and realign curriculum for preparing the new generation of nursing scientists (Grace et al., 2016; Henly et al., 2015a).

\section{Conclusion}

To draw a new image of nursing science, nursing theorists and nursing scholars should consider carefully to preserve the identity of nursing science. At the same time, they should ponder to enhance the older nursing paradigms to the contemporary one. Nursing scholars are facing a challenging question that should nursing science continue holding on a strong traditional practice or should shift it to new paradigms of thinking and acting? (Butts, Rich, \& Fawcett, 2012). Nowadays clients' behavior in terms of self-monitoring and self-management is being totally changed because of the impact of high technology devices on users' health behavior (Henly et al., 2015a). What should be a standpoint epistemology of nursing science in the next decade?

The revolution of nursing science occurs overtime since the Nightingale's era. The Nightingale's theory was recorded as the first scientific revolution in nursing (Koffi \& Fawcett, 2016). Even though nursing science is currently mature, unfortunately, anomalies of nursing science were found and represented in the literature. Therefore, nursing scholars should take actions by reconstruction the malfunction and crisis of the older nursing paradigms. As a result, the revolution of nursing science will generate the new nursing paradigms and allow nursing scholars respond to a new world of nursing science.

\section{Competing Interests Statement}

The authors declare that there are no competing or potential conflicts of interest.

\section{References}

Barrett, E. A. M. (2002). What is nursing science? Nursing Science Quarterly, 15(1), 51-60. https://doi.org/10.1177/08943180222108778 
Barrett, E. A. M. (2017). Again, what is nursing science? Nursing Science Quarterly, 30(2), 129-133. https://doi.org/10.1177/0894318417693313

Butts, J. B., Rich, K. L., \& Fawcett, J. (2012). The Future of nursing: How important is discipline-specific knowledge? A conversation with Jacqueline Fawcett. Nursing Science Quarterly, 25(2), 151-154. https://doi.org/10.1177/0894318412437955

Conley, Y. P., Heitkemper, M., McCarthy, D., Anderson, C. M., Corwin, E. J., Daack-Hirsch, S., ... \& Voss, J. (2015). Educating future nursing scientists: Recommendations for integrating omics content in $\mathrm{PhD}$ programs. Nursing Outlook, 63(4), 417-427. https://doi.org/10.1016/j.outlook.2015.06.006

Daly, J. (1997). What is nursing science? An international dialogue. Nursing Science Quarterly: Scholarly Dialogue, 10(1), 10-13. https://doi.org/10.1177/089431849701000105

Grace, P. J., Willis, D. G., Roy, C., \& Jones, D. A. (2016). Profession at the crossroads: A dialog concerning the preparation of nursing scholars and leaders. Nursing Outlook, 64, 61-70. https://doi.org/10.1016/j.outlook.2015.10.002

Grady, P. A., \& Gough, L. L. (2015). Nursing science: Claiming the future. Journal of Nursing Scholarship, 47(6), 512-521. https://doi.org/10.1111/jnu. 12170

Henly, S. J. (2011). The future history of nursing science: 2026. Nursing Research, 60(2), 81. https://doi.org/10.1097/NNR.0b013e3182123307

Henly, S. J., McCarthy, D. O., Wyman, J. F., Stone, P. W., Redeker, N. S., McCarthy, A. M., ... \& Conley, Y. P. (2015a). Integrating emerging areas of nursing science into PhD programs. Nursing Outlook, 63(4), 408-416. https://doi.org/10.1016/j.outlook.2015.04.010

Henly, S. J., McCarthy, D. O., Wyman, J. F., Alt-White, A. C., Stone, P. W., McCarthy, A. M., ... \& Moore, S. M. (2015b). Emerging areas of nursing science and $\mathrm{PhD}$ education for the 21 st century: Response to commentaries. Nursing outlook, 63(4), 439-445. https://doi.org/10.1016/j.outlook.2015.05.003

Hinshaw, A. S. (1989). Nursing science: The challenge to develop knowledge. Nursing Science Quarterly, 2(4), 162-171. https://doi.org/10.1177/089431848900200406

Jankowski, N. W. (2007). Exploring e-science: An introduction. Journal of Computer-Mediated Communication, 12(2), 549-562. https://doi.org/10.1111/j.1083-6101.2007.00337.x

Koffi, K., \& Fawcwtt, J. (2016). The two-nursing disciplinary scientific revolutions: Florence Nightingale and Martha E. Rogers. Nursing Science Quarterly, 29(3), 247-250. https://doi.org/10.1177/0894318416648782

Kvasz, L. (2014). Kuhn's structure of scientific revolutions between sociology and Epistemology. Studies in History and Philosophy of Science, 46, 78-84. https://doi.org/10.1016/j.shpsa.2014.02.006

Parse, R. R. et al. (2000). Nursing theory-guided practice: A definition. Nursing Science Quarterly, 13(2), 177. https://doi.org/10.1177/08943180022107474

Parse, R. R. (2015a). Nursing science or is it the science of nursing? Nursing Science Quarterly, 28(2), 101-102. https://doi.org/10.1177/0894318415571617

Parse, R. R. (2015b). Nursing: A basic or applied science. Nursing Science Quarterly, 28(3), 181-182. https://doi.org/10.1177/0894318415585636

Parse, R. R. (2016). Where have all the nursing theories gone? Nursing Science Quarterly, 29(2), 101-102. https://doi.org/10.1177/0894318416636392

Peterson, S. J., \& Bredow, T. S. (2009). Middle range theories: Application to nursing research ( $2^{\text {nd }}$ ed.). Philadelphia, PA: Wolters Klunn Health.

Salzmann-Erikson, M., \& Eriksson, H. (2015). The rise of the avatar: Virtual dimensions of 'the human' in nursing science. Nordic Journal of Nursing Research, 35(3), 1-7. https://doi.org/10.1177/0107408315589462

Salzmann-Erikson, M., \& Eriksson, H. (2016). Cyber nursing: A conceptual framework. Nordic Journal of Research in Nursing, 21(7), 505-514. https://doi.org/10.1177/1744987116661378

Takahashi, T. (1997). What is nursing science? An international dialogue. Nursing Science Quarterly: Scholarly Dialogue, 10(1), 10-13. https://doi.org/10.1177/089431849701000105

Toboly, A. T. (2017). Kuhn, Kuhn, Kuhn: New Wine into Old Bottles? J Gen Philos Sci, 48, 601-604. https://doi.org/10.1007/s10838-016-9359-3 
Wall, M. L., \& Carraro, T. E. (2009). Kuhn's revolutionary theory and its influence on the constructions of nursing knowledge. Rev Latino-am https://doi.org/10.1590/S0104-11692009000300021

\section{Copyrights}

Copyright for this article is retained by the author(s), with first publication rights granted to the journal.

This is an open-access article distributed under the terms and conditions of the Creative Commons Attribution license (http://creativecommons.org/licenses/by/4.0/). 